ARTICLE

\title{
Asymmetric total synthesis of yuzurimine-type Daphniphyllum alkaloid (+)-caldaphnidine J
}

Lian-Dong Guo (i) 1, Yan Zhang (10 1,2, Jingping Hu (1) 1,2, Chengqing Ning $\mathbb{B}^{1}$, Heyifei Fu', Yuye Chen (1) ${ }^{1} \&$ Jing $X u(1){ }^{1 凶}$

Ever since Hirata's report of yuzurimine in 1966, nearly fifty yuzurimine-type alkaloids have been isolated, which formed the largest subfamily of the Daphniphyllum alkaloids. Despite extensive synthetic studies towards this synthetically challenging and biologically intriguing family, no total synthesis of any yuzurimine-type alkaloids has been achieved to date. Here, the first enantioselective total synthesis of $(+)$-caldaphnidine J, a highly complex yuzuriminetype Daphniphyllum alkaloid, is described. Key transformations of this approach include a highly regioselective Pd-catalyzed hydroformylation, a samarium(II)-mediated pinacol coupling, and a one-pot Swern oxidation/ketene dithioacetal Prins reaction. Our approach paves the way for the synthesis of other yuzurimine-type alkaloids and related natural products.

\footnotetext{
${ }^{1}$ Shenzhen Grubbs Institute and Department of Chemistry and Guangdong Provincial Key Laboratory of Catalysis, Southern University of Science and Technology, 518055 Shenzhen, China. ${ }^{2}$ These authors contributed equally: Yan Zhang, Jingping Hu. ${ }^{\varpi_{e}}$ mail: xuj@sustech.edu.cn
} 
T he plant family of genus Daphniphyllum has produced a wide range of complex caged natural products-the Daphniphyllum alkaloids ${ }^{1-4}$. Owing to their challenging chemical structures and interesting biological profiles (such as anticarcinogenic, neurotrophic, and anti-HIV activity) $)^{5,6}$, these alkaloids have drawn much attention from the synthetic community ${ }^{1,3,4}$. Depending on the taxonomy, the diversified structures of the Daphniphyllum alkaloids can be categorized into 13-35 subfamilies ${ }^{1,4,7}$. To date, about 20 elegant total syntheses of the Daphniphyllum alkaloids, from seven subfamilies, have been reported by the research groups of Heathcock ${ }^{8-15}$, Carreira ${ }^{16}$, $\mathrm{Li}^{17-20}$, Smith ${ }^{21,22}$, Hanessian ${ }^{23}$, Fukuyama/Yokoshima ${ }^{24}$, Zhai $^{25}$, Dixon $^{26}$, $\mathrm{Qiu}^{27}, \mathrm{Gao}^{28}$, and Sarpong ${ }^{29,30}$ groups, respectively. Moreover, our group has recently accomplished the asymmetric total syntheses of himalensine $\mathrm{A}^{31}$, dapholdhamine $\mathrm{B}^{32}$, and caldaphnidine $\mathrm{O}^{33}$. However, despite extensive synthetic stu$\operatorname{dies}^{34-48}$, total synthesis of yuzurimine-type alkaloids-the largest subfamily of the Daphniphyllum alkaloids-has not been achieved so far.

Since the milestone achievement by Hirata in $1966^{49}$, nearly 50 yuzurimine-type alkaloids were isolated, which account for almost one-sixth of all known Daphniphyllum alkaloids to date. It is recognized that the members of this subfamily share a unique, highly complex and caged hexacyclic skeleton (Fig. 1). Caldaphnidine J, our target molecule, was isolated by the Yue group in $2008^{50}$. It possesses a hexacyclic scaffold with six contiguous stereogenic centers, two quaternary centers, and an $\alpha, \beta, \gamma, \delta$ unsaturated carboxylic ester thus signifying a formidable synthetic challenge. Following our long-lasting interest in the synthesis of the Daphniphyllum alkaloids ${ }^{31-33,51,52}$, we now wish to report an asymmetric total synthesis of yuzurimine-type alkaloid, $(+)$-caldaphnidine J. Our approach is featured with a Pd-catalyzed regioselective hydroformylation that furnishes the critical aldehyde motif, and the construction of the $5 / 5$ bicyclic system using a $\mathrm{SmI}_{2}$-promoted pinacol coupling and a one-pot Swern oxidation/ketene dithioacetal Prins reaction. Other notable attempts toward the $7 / 5$ bicycle in our target molecule are also discussed.

\section{Results}

Retrosynthetic analysis. As shown in Fig. 2, our retrosynthetic analysis indicates that $(+)$-caldaphnidine J could be converted from the intermediate $\mathbf{1}$ via $\mathrm{Ni}(0)$-mediated reductive coupling reaction ${ }^{53}$. It was further envisioned that a ketene dithioacetal Prins reaction ${ }^{54-57}$ would form the cyclopentene moiety in $\mathbf{1}$, while compound $\mathbf{2}$ might be produced from the enyne acetal $\mathbf{3}$ via a carbocyclization cascade ${ }^{58}$. Lastly, compound 3 could be synthesized via a facile ring cleavage from the readily available chiral building block, tricyclic ketone $\mathbf{4}^{33}$.

Initial synthetic studies toward the $7 / 5$ ring system. The first stage of our investigation focused on the critical $7 / 5$ ring scaffold assembly (Fig. 3). The treatment of the known tricycle $4^{33}$ with $\mathrm{MeMgBr}$ in the presence of $\mathrm{CeCl}_{3}$ was followed by an oxidative cleavage of the intermediate diol producing dicarbonyl 5. Subsequently, $\mathbf{5}$ was subjected to Wittig conditions to yield the enol methyl ether, which was then transformed into acetal 6. Following Stang's protocol ${ }^{59}$, ketone motif in $\mathbf{6}$ was converted into an enol triflate, which was then treated with pyridine affording alkyne 7. Subsequent Sonogashira coupling yielded enyne acetal 3. Inspired by Saá's impressive Nazarov carbocyclization cascade $^{58}$, enyne acetal 3 was treated with Brønsted acids such as TFA or $\mathrm{HBF}_{4} \bullet \mathrm{OEt}_{2}$. However, none of the desired hydroazulenone $\mathbf{8}$ was detected. Alternatively, attempting to use a formic acid-promoted cyclization ${ }^{60,61}$ between the thioalkyne and

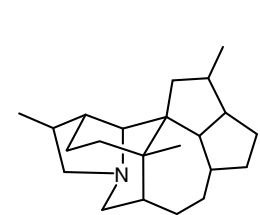

Common skeleton of Yuzurimine-type alkaloids

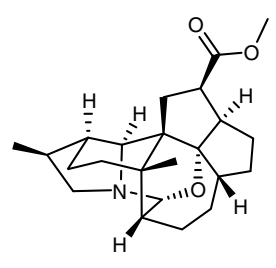

Daphcalycine

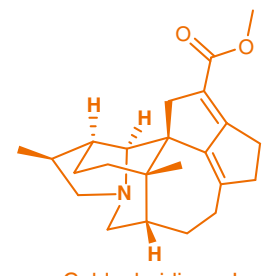

Caldaphnidine $\mathrm{J}$

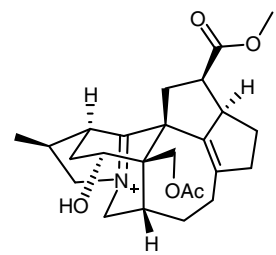

Daphnezomine J

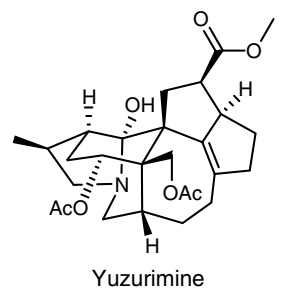

Fig. 1 Yuzurimine-type Daphniphyllum alkaloids. Our target molecule, caldaphnidine J, are highlighted in color, which posed a formidable synthetic challenge for accessing its total synthesis.
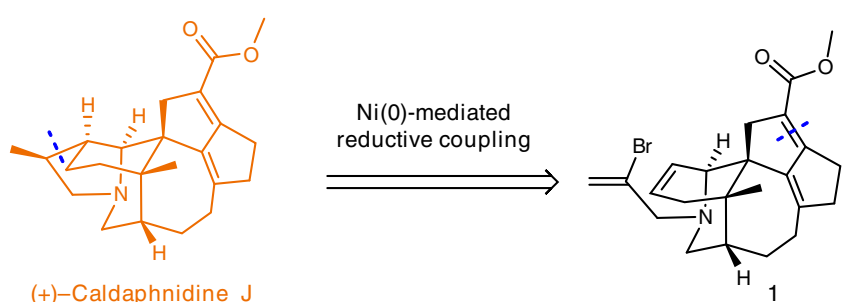

(+)-Caldaphnidine $\mathrm{J}$

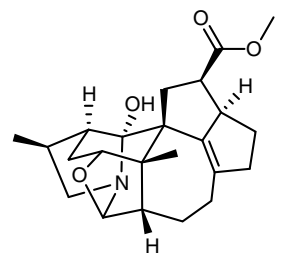

Yunnandaphnine $\mathrm{E}$

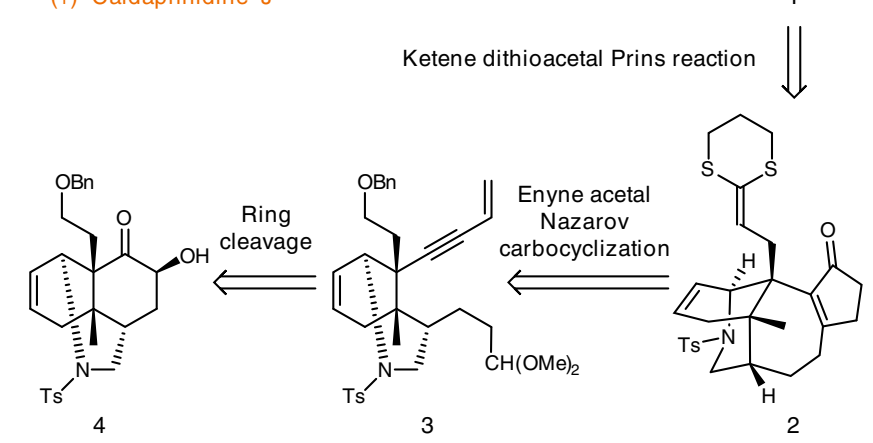

Fig. 2 Retrosynthetic analysis of $(+)$-caldaphnidine $\mathbf{J}$. The key disconnections include a $\mathrm{Ni}(0)$-mediated reductive coupling reaction, a ketene dithioacetal Prins reaction, an enyne acetal Nazarov carbocyclization and a ring cleavage strategy.

the acetal motifs in compound 9 returned only messy mixtures. It was postulated that the desired cyclization was prevented by the steric bulk at C-8 (caldaphnidine J numbering).

On the other hand, aldol condensation of $\mathbf{5}$ yielded solely cyclopentene 11, but not cycloheptenone 12 possessing the desired seven-membered ring (Fig. 3). Instead, selective reduction of the aldehyde motif in $\mathbf{5}$ followed by an Appel reaction afforded the corresponding alkyl iodide, which then underwent an intramolecular alkylation upon treatment with LDA yielding the desired tricycle 13 in $69 \%$ overall yield. Inspired by Smith's impressive work ${ }^{21,22}$, it was envisioned that a carbonylative Stille coupling reaction followed by a Nazarov cyclization would elaborate the desired bicycle $\mathbf{8}$. While ketone $\mathbf{1 3}$ is quite similar to Smith's substrates ${ }^{21,22}$, in our hands all of the deprotonation attempts failed resulting in no reaction at negative and decomposition events at elevated temperatures. It is quite possible that the corresponding enol triflate $\mathbf{1 4}$ is unstable by introducing increased ring strain to the $6 / 6 / 7$ tricyclic system. 


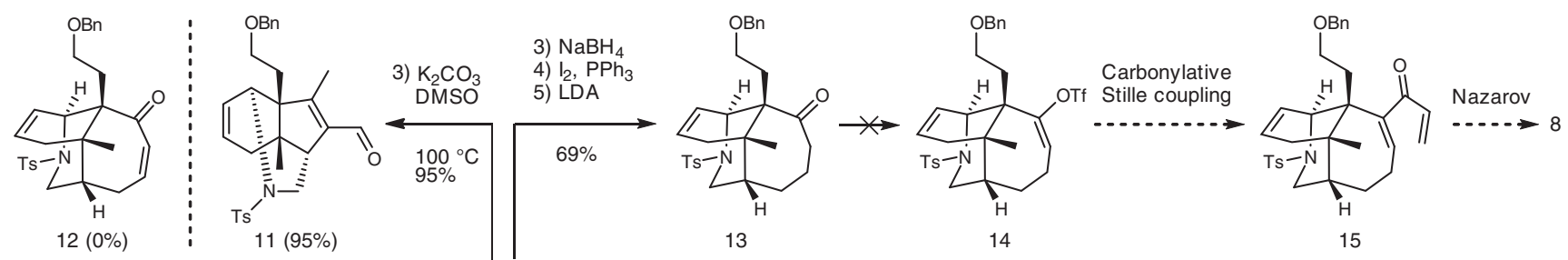

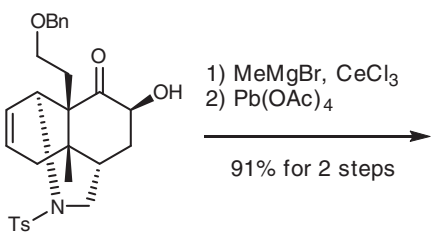

$( \pm)-4$, known

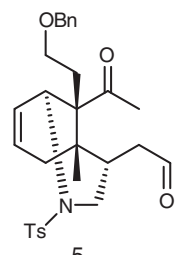

5

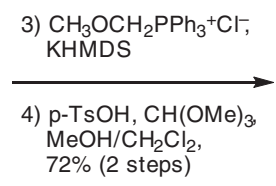

$72 \%$ (2 steps)
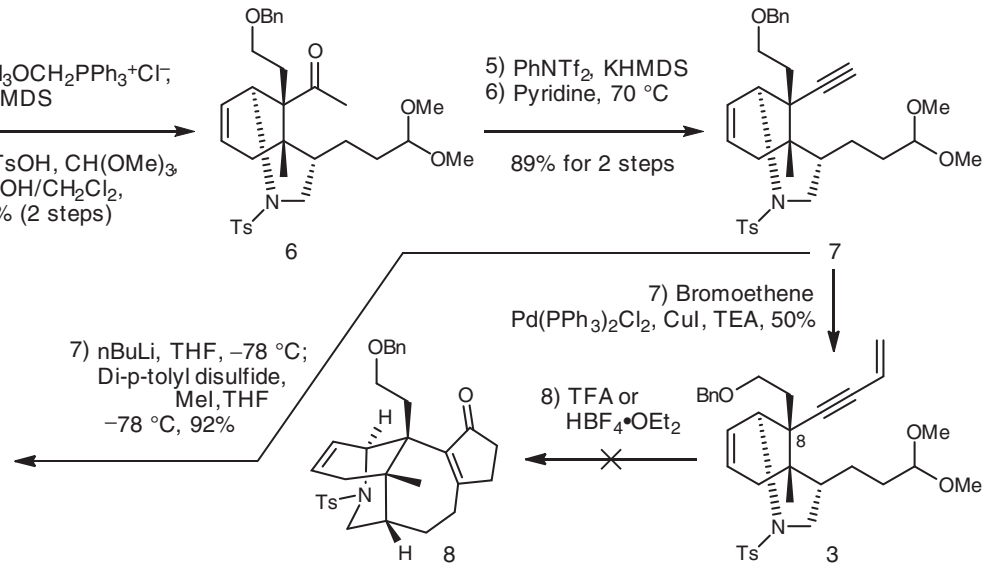

7) Bromoethene
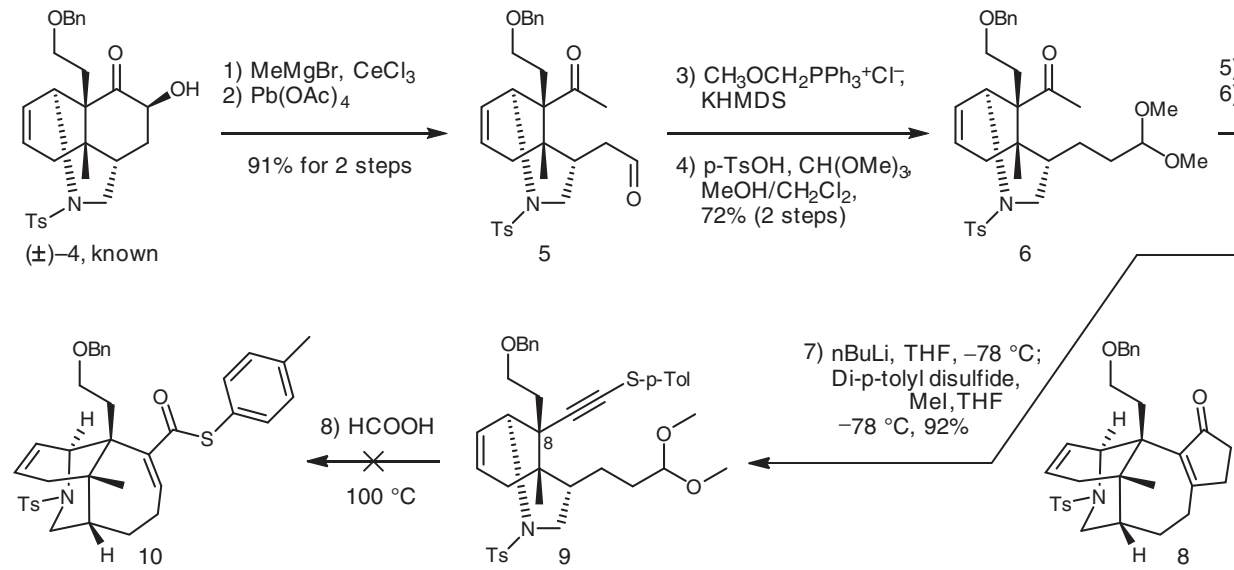

Ts 9

Fig. 3 Initial studies towards the 7/5 ring system. Bn benzyl, KHMDS potassium bis(trimethylsilyl)amide, LDA lithium diisopropylamide, Tf trifluoromethanesulfonyl, TFA trifluoroacetic acid, TEA triethylamine, Ts toluenesulfonyl.

Total synthesis of $(+)$-caldaphnidine $\mathbf{J}$. The fruitless synthetic attempts toward the $7 / 5$ bicyclic ring scaffold forced us to use the similar strategy to the total synthesis of caldaphnidine $\mathrm{O}^{33}$. As depicted in Fig. 4, treatment of ketone 4 with AllylMgBr in the presence of $\mathrm{CeCl}_{3}$ furnished a diol intermediate, which was subjected to a $\mathrm{Pb}(\mathrm{IV})$-mediated oxidative cleavage. A follow-up $\mathrm{NaBH}_{4}$ reduction yielded a somewhat unstable $\beta, \gamma$-unsaturated ketone 16, which was immediately subjected to iodination producing alkyl iodide 17. Subsequently, treating 17 with LDA triggered an intramolecular alkylation to afford $\alpha$-vinyl functionalized ketones 18a (minor, 25\%) and 18b (major, 50\%). The stereoconfigurations of $\mathbf{1 8 a}$ and $\mathbf{1 8 b}$ were assigned at later stage, according to a single-crystal X-ray diffraction (XRD) data of compound 22. Initially, we envisioned to subject both isomers of 18 to a Pd-catalyzed carbonylative cyclization ${ }^{62,63}$, however preparation of the corresponding enol triflate failed. Alternatively, the terminal alkene motif in $\mathbf{1 8 b}$ was regioselectively hydroformylated following Shi's protocol furnishing aldehyde 19 in $75 \%$ yield ${ }^{64}$. Any branched side products were not detected during this transformation. Although aldehyde 19 could also be synthesized via rather routine methods ${ }^{33}$, the intrinsic structural complexity of substrate $\mathbf{1 8 b}$ enabled the exciting opportunity for expanding the substrate scope for Shi's regioselective hydroformylation. Subsequently, an intramolecular pinacol coupling reaction mediated by $\mathrm{SmI}_{2}$ furnished diol 20, which possesses the essential 7/5 bicyclic ring scaffold. Selective acylation of the secondary hydroxyl, followed by DDQ-mediated debenzylation afforded primary alcohol 21, which was then converted into aldehyde 22 using Dess-Martin oxidation. The identity of $\mathbf{2 2}$ was unambiguously confirmed via XRD analysis. A Horner-Wadsworth-Emmons homologation using phosphonate $\mathbf{2 3}^{32,33,65}$, followed by one-pot DIBAL-H reduction afforded ketene dithioacetal 25 in $94 \%$ yield. Notably, the intermediate acetate $\mathbf{2 4}$ gave a single crystal suitable for XRD analysis.

At this stage, aldol-type ${ }^{16,21,22}$ or Prins-type reaction was required to form the critical $\mathrm{C}_{14}-\mathrm{C}_{15}$ bond in $\mathbf{2 6}$. However, ketene dithioacetal-involved aldol- or Prins-type reactions are poorly explored. There are only a handful of examples reported in an intermolecular manner ${ }^{54-57}$. Inspired by these investigations, it was envisaged that oxidation of the hydroxyl at C-15 would produce the corresponding ketone motif, and the following ketene dithioacetal Prins-type reaction should form the crucial $\mathrm{C}-\mathrm{C}$ bond thus constructing the desired pentacycle. To our delight, subjecting diol 25 to a TFAA/DMSO-mediated Swern oxidation triggered the desired cyclization of the dithioacetal ketene onto a newly formed ketone moiety. The ultimate product 26 was then formed by 1,2-addition of dimethyl sulfide onto the sulfonium intermediate, followed by demethylation ${ }^{66}$. While all reported examples of intermolecular ketene dithioacetal aldol/ Prins-type reactions were performed under strong Lewis acid conditions such as $\mathrm{BF}_{3} \bullet \mathrm{Et}_{2} \mathrm{O}, \mathrm{TiCl}_{4}$, and TMSOTf ${ }^{54-57}$, the addition of a strong Lewis acid were not necessary for our ketone intermediate derived from 25. Moreover, using other oxidants such as $(\mathrm{COCl})_{2} / \mathrm{DMSO}, \mathrm{Py} \bullet \mathrm{SO}_{3} / \mathrm{DMSO}, \mathrm{NCS} / \mathrm{DMSO}$, or $\mathrm{Ac}_{2} \mathrm{O} /$ DMSO resulted in decomposition of $\mathbf{2 5}$ giving poorly identifiable side products. The 2-(methylthio)-1,3-dithiane moiety in $\mathbf{2 6}$ was then smoothly transformed to the methyl ester 27 by the action of methanolic iodine. Selective elimination of the hydroxyl at C-15 of 27 was required to avoid any possible side reaction between the a-aminyl radical and the $\mathrm{C}_{9}-\mathrm{C}_{10}$ alkene moiety in a later stage of our synthesis ${ }^{33}$. Gratifyingly, treating cis-diol 27 with $\mathrm{SOCl}_{2}$ yielded the dialkyl sulfite $\mathbf{2 8}$, which upon treatment with DBU suffered $\mathrm{E} 2 \mathrm{cB}$ elimination providing the hope-for allylic alcohol 29. Removal of the tosyl appendage in 29 was followed by a onepot alkylation to yield vinyl bromide 30. This vinyl bromide substrate enabled the investigation of the $\mathrm{Ni}(0)$-catalyzed $\mathrm{C}-\mathrm{C}$ coupling and the Tin-mediated radical cyclization approaches. A $\mathrm{Ni}(0)$-mediated reductive coupling of $\mathbf{3 0} \mathbf{0}^{53}$, unfortunately, failed to produce 31 but only messy results. There was not any identifiable product that could be isolated. LC-MS indicates only a trace amount of the desired hexacycle 31. Alternatively, subjecting 30 to an $\mathrm{AIBN} / \mathrm{Bu}_{3} \mathrm{SnH}$-mediated radical cyclization assembled the key tetrahydropyrrole ring in 31 . The acidic workup promoted the elimination of the C-9 hydroxyl group to 


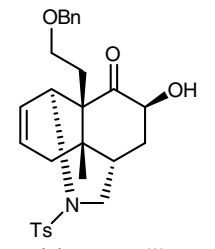

(+) -4 , readily available synthon

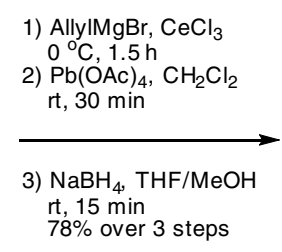

$78 \%$ over 3 steps

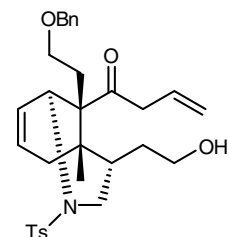

16

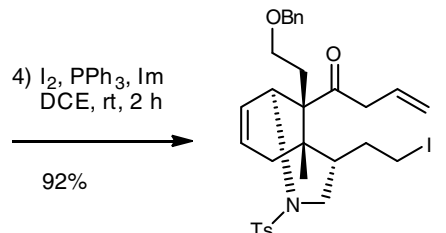

5) $\mathrm{LDA},-50^{\circ} \mathrm{C}$ to
$-20{ }^{\circ} \mathrm{C}, 3 \mathrm{~h}$<smiles>[194Pb]</smiles>

$75 \%, 18 a: 18 b=1: 2$

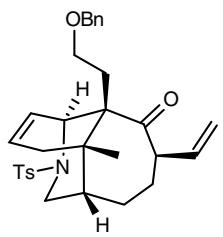

$18 \mathrm{a}$

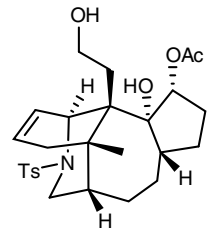

8) $\mathrm{Ac}_{2} \mathrm{O}, \mathrm{Py}, \mathrm{DMAP}, \mathrm{rt}, 14 \mathrm{~h}$ 9) $\mathrm{DDQ}, \mathrm{CH}_{2} \mathrm{Cl}_{2} / \mathrm{H}_{2} \mathrm{O}, \mathrm{rt}, 25$ $81 \%$ for 2 steps

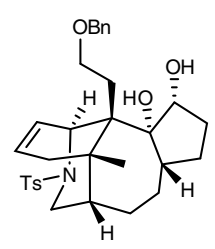

20
7) $\mathrm{Sml}_{2}, \mathrm{THF}$

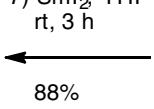

Sm(II)-mediated
Pinacol coupling

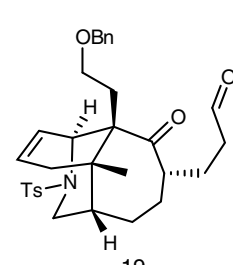

19

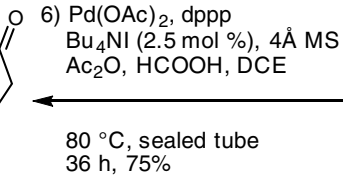

$36 \mathrm{~h}, 75 \%$ Pd-catalyzed
regioselective
hydroformylation

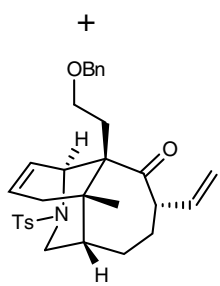

$18 \mathrm{~b}$

10) Dess-Martin periodinane, $\mathrm{NaHCO}_{3}$ $\mathrm{CH}_{2} \mathrm{Cl}_{2}, \mathrm{rt}, 1 \mathrm{~h}, 95 \%$
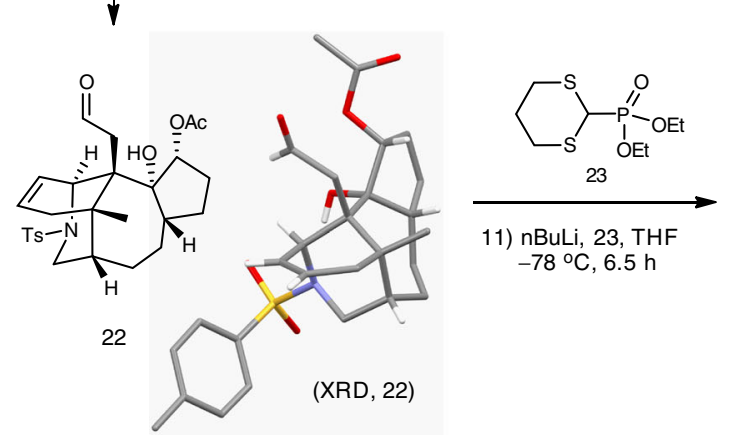

11) nBuLi, $23, \mathrm{THF}$ $-78^{\circ} \mathrm{C}, 6.5 \mathrm{~h}$

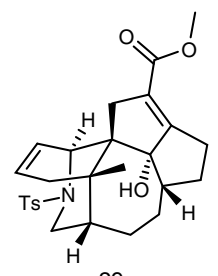

29
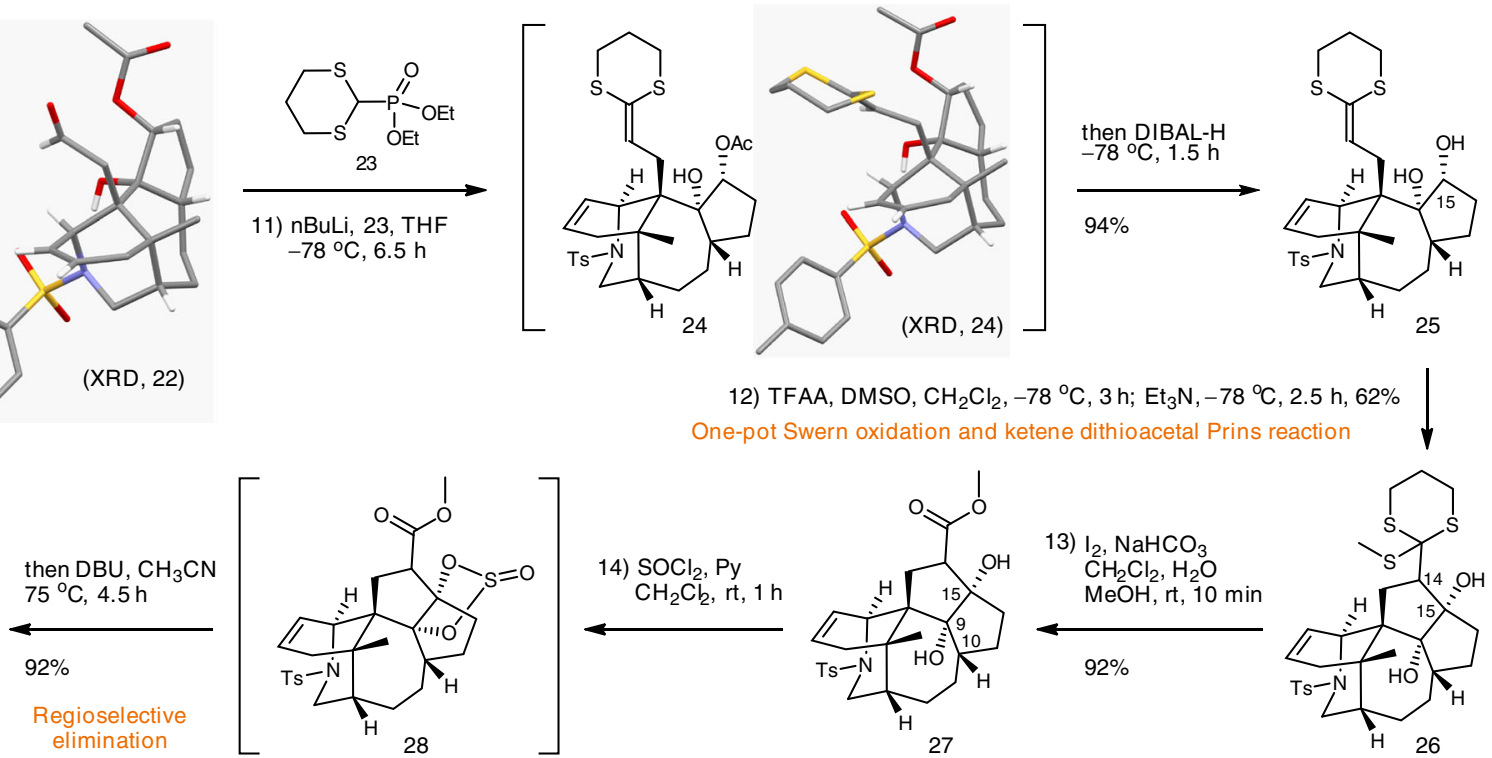

12) TFAA, DMSO, $\mathrm{CH}_{2} \mathrm{Cl}_{2},-78^{\circ} \mathrm{C}, 3 \mathrm{~h} ; \mathrm{Et}_{3} \mathrm{~N},-78{ }^{\circ} \mathrm{C}, 2.5 \mathrm{~h}, 62 \%$ One-pot Swern oxidation and ketene dithioacetal Prins reaction

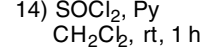

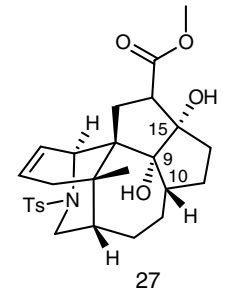

13) $\mathrm{I}_{2} \mathrm{NaHCO}_{3}$ $\mathrm{CH}_{2} \mathrm{Cl}_{2}, \mathrm{H}_{2} \mathrm{O}$ $\mathrm{MeOH}, \mathrm{rt}, 10 \mathrm{~min}$

$92 \%$

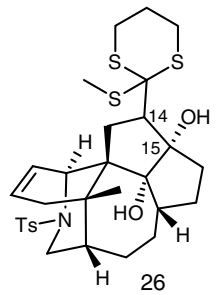

15) Na-Naph., DME, $10 \mathrm{~min} ; \mathrm{MeOH},-78{ }^{\circ} \mathrm{C}$ 2,3-dibromopropene, rt, $3 \mathrm{~h}, 70 \%$

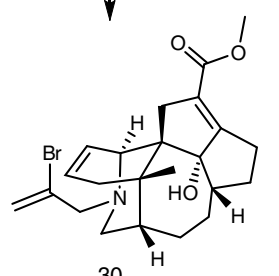

30

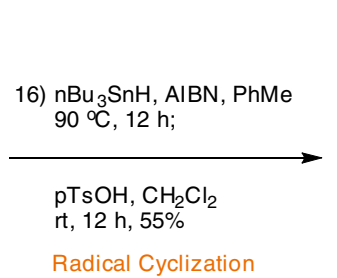

Radical Cyclization

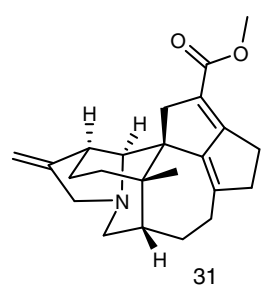

31
17) Crabtree's catalyst, $\mathrm{H}_{2} / \mathrm{Ar}(1: 1)$ $\mathrm{CH}_{2} \mathrm{Cl}_{2}, \mathrm{rt}, 17 \mathrm{~h}$

\section{$81 \%$ for the desired} diastereomer $(\mathrm{dr}=8: 1)$

Diastereoselective Hydrogenation

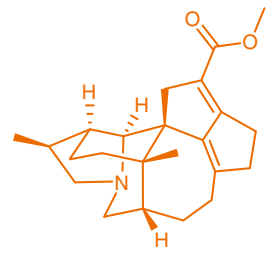

(+)-Caldaphnidine J

Fig. 4 Total synthesis of $(+)$-caldaphnidine J. Key transformations were highlighted in colored text. Ac acetyl, AIBN azodiisobutyronitrile, DBU 1,8diazabicyclo[5.4.0] undec-7-ene, DCE dichloroethane, DDQ 2,3-dichloro-5,6-dicyano-1,4-benzoquinone, DIBAL-H diisobutylaluminium hydride, DMAP 4dimethylaminopyridine, DME 1,2-dimethoxyethane, dppp 1,3-bis(diphenylphosphino) propane, Naph. naphthalene, TFAA trifluoroacetic anhydride.

yield the conjugated diene. Lastly, a highly regio- and diastereoselective hydrogenation $\left(\mathrm{H}_{2} / \mathrm{Ar}=1: 1\right.$, Crabtree's catalyst) of 31 successfully produced (+)-caldaphnidine $\mathrm{J}$ in $81 \%$ yield $(\mathrm{dr}=8: 1)$. The synthetic $(+)$-caldaphnidine $\mathrm{J}$ gave spectral characteristics $\left({ }^{1} \mathrm{H}\right.$ - and ${ }^{13} \mathrm{C}-\mathrm{NMR}$ spectroscopy and HRMS data) consistent with those of the naturally occurring $(+)$-caldaphnidine $\mathrm{J}$, while the optical rotation is also in perfect agreement with that of the natural product (synthetic: $[\alpha]_{\mathrm{D}}{ }^{20}=+60.0(c=0.1$ in $\mathrm{MeOH})$; natural: $[\alpha]_{\mathrm{D}}{ }^{20}=+57.0(c=0.2 \text { in } \mathrm{MeOH})^{50}$.

\section{Discussion}

Owing to their extremely challenging structures, the synthesis of yuzurimine-type Daphniphyllum alkaloids remain unexplored for more than half a century. These intriguing alkaloids provide ideal platforms for developing and probing various synthetic strategies and methods. In this paper, we have accomplished an asymmetric synthesis of highly challenging yuzurimine-type Daphniphyllum alkaloid $(+)$-caldaphnidine $\mathrm{J}$ in 17 steps from readily available chiral synthon $(+)-\mathbf{4}$. This work achieves the synthesis of a 
member of the largest yet unexplored subfamily of Daphniphyllum alkaloids. The highlights of our synthesis include: (1) a highly regioselective Pd-catalyzed hydroformylation reaction; (2) a Sm(II)-mediated pinacol coupling that produced a highly challenging $7 / 5$ bicyclic system while all other attempts failed; (3) a one-pot Swern oxidation/ketene dithioacetal Prins reaction; (4) a regioselective elimination through a cyclic sulfite intermediate, and (5) a radical cyclization reaction that rapidly constructed the tetrahydropyrrole motif. The synthetic strategies and methods should inspire further advances in the synthesis of diverse Daphniphyllum alkaloids and related natural products.

\section{Methods}

General. Unless indicated, all commercially available reagents and anhydrous solvents were purchased at the highest commercial quality and were used as received without further purification. All non-aqueous reactions were carried out under argon atmosphere using dry glassware that had been flame-dried under a stream of argon unless otherwise noted. Tetrahydrofuran (THF) was distilled from sodium benzophenone under argon atmosphere. Dichloromethane (DCM) was distilled from calcium hydride. Reactions were monitored by thin-layer chromatography (TLC; GF254) using plates supplied by Yantai Chemicals (China) and visualized under UV or by staining with an ethanolic solution of phosphomolybdic acid, cerium sulfate or iodine. Flash column chromatography was performed using silica gel (particle size, $0.040-0.063 \mathrm{~mm}$ ).

NMR spectra were recorded on a Bruker AV400 MHz or a Bruker AscendTM $500 \mathrm{MHz}$ instrument and calibrated using residual undeuterated chloroform, methanol, and dichloromethane in $\mathrm{CDCl}_{3}(\delta \mathrm{H}=7.26 \mathrm{ppm}, \delta \mathrm{C}=77.0 \mathrm{ppm})$, MeOD-d4 $(\delta \mathrm{H}=3.31 \mathrm{ppm}, \delta \mathrm{C}=49.0 \mathrm{ppm})$, or $\mathrm{CD}_{2} \mathrm{Cl}_{2}(\delta \mathrm{H}=5.32 \mathrm{ppm}, \delta \mathrm{C}=$ $53.84 \mathrm{ppm})$ as an internal reference. The following abbreviations were used to describe signal multiplicities: $s$, singlet; $d$, doublet; $t$, triplet; $d t$, double triplet; $d d d$, doublet of double doublet; ddt, doublet of double triplet; m, multiplet. Highresolution mass spectra (HRMS) were recorded on a Thermo Scientific Q Exactive Hybrid Quadrupole Orbitrap mass spectrometer.

Experimental data. For NMR spectra of synthetic intermediates, see Supplementary Figs. 3-57. For the experimental procedures and spectroscopic and physical data of compounds and the crystallographic data of compound 22 and $\mathbf{2 4}$, see Supplementary Methods.

Supplementary Information accompanies this manuscript.

\section{Data availability}

The X-ray crystallographic coordinates for structures $\mathbf{2 2}$ and $\mathbf{2 4}$ reported in this study have been deposited at the Cambridge Crystallographic Data Centre (CCDC) with the accession codes CCDC 1986889 and CCDC 1986960 (www.ccdc.cam.ac.uk/data_request/ cif), respectively. We declare that all other relevant data supporting the findings of this study are available within the article and its Supplementary Information files.

Received: 19 April 2020; Accepted: 22 June 2020;

Published online: 15 July 2020

\section{References}

1. Kobayashi, J. \& Kubota, T. The Daphniphyllum alkaloids. Nat. Prod. Rep. 26, 936-962 (2009).

2. Yang, S.-P. \& Yue, J.-M. Discovery of structurally diverse and bioactive compounds from plant resources in China. Acta Pharmacol. Sin. 33, 1147-1158 (2012).

3. Kang, B., Jakubec, P. \& Dixon, D. J. Strategies towards the synthesis of calyciphylline A-type Daphniphyllum alkaloids. Nat. Prod. Rep. 31, 550-562 (2014).

4. Chattopadhyay, A. K. \& Hanessian, S. Recent progress in the chemistry of Daphniphyllum alkaloids. Chem. Rev. 117, 4104-4146 (2017)

5. Wu, H. et al. Daphniphyllum alkaloids: recent findings on chemistry and pharmacology. Planta Med. 79, 1589-1598 (2013).

6. Xu, J.-B. et al. Logeracemin A, an anti-HIV Daphniphyllum alkaloid dimer with a new carbon skeleton from Daphniphyllum longeracemosum. J. Am. Chem. Soc. 136, 7631-7633 (2014).

7. Li, Z.-Y. \& Guo, Y.-W. Progress in the study of Daphniphyllum alkaloids. Youji Huaxue 27, 565 (2007)

8. Piettre, S. \& Heathcock, C. H. Biomimetic total synthesis of protodaphniphylline. Science 248, 1532-1534 (1990).

9. Heathcock, C. H., Davidsen, S. K., Mills, S. \& Sanner, M. A. Total synthesis of (士)-methyl homodaphniphyllate. J. Am. Chem. Soc. 108, 5650-5651 (1986).
10. Ruggeri, R. B. \& Heathcock, C. H. Daphniphyllum alkaloids. Part 7. Biomimetic total synthesis of ( \pm )-methyl homodaphniphyllate. J. Org. Chem. 55, 3714-3715 (1990).

11. Heathcock, C. H., Kath, J. C. \& Ruggeri, R. B. Daphniphyllum alkaloids. 16 Total synthesis of $(+)$-codaphniphylline. J. Org. Chem. 60, 1120-1130 (1995)

12. Ruggeri, R. B., Hansen, M. M. \& Heathcock, C. H. Total synthesis of $( \pm)$-methyl homosecodaphniphyllate. A remarkable new tetracyclization reaction. J. Am. Chem. Soc. 110, 8734-8736 (1988).

13. Stafford, J. A. \& Heathcock, C. H. Daphniphyllum alkaloids. Part 8. Asymmetric total synthesis of (-)-secodaphniphylline. J. Org. Chem. 55, 5433-5434 (1990)

14. Heathcock, C. H., Stafford, J. A. \& Clark, D. L. Daphniphyllum alkaloids. 14. Total synthesis of ( \pm )-bukittinggine. J. Org. Chem. 57, 2575-2585 (1992).

15. Ruggeri, R. B., McClure, K. F. \& Heathcock, C. H. Daphniphyllum alkaloids Part 5. Total synthesis of $( \pm)$-daphnilactone A: a novel fragmentation reaction. J. Am. Chem. Soc. 111, 1530-1531 (1989).

16. Weiss, M. E. \& Carreira, E. M. Total synthesis of (+)-daphmanidin E. Angew. Chem. Int. Ed. 50, 11501-11505 (2011).

17. Lu, Z. Y., Li, Y., Deng, J. \& Li, A. Total synthesis of the Daphniphyllum alkaloid daphenylline. Nat. Chem. 5, 679-684 (2013).

18. Li, J., Zhang, W. H., Zhang, F., Chen, Y. \& Li, A. Total synthesis of longeracinphyllin A. J. Am. Chem. Soc. 139, 14893-14896 (2017).

19. Chen, Y., Zhang, W. H., Ren, L., Li, J. \& Li, A. Total syntheses of daphenylline, daphnipaxianine A, and himalenine D. Angew. Chem. Int. Ed. 57, 952-956. (2018)

20. Zhang, W. H. et al. Total synthesis of hybridaphniphylline B. J. Am. Chem. Soc. 140, 4227-4231 (2018).

21. Shvartsbart, A. \& Smith, A. B. III Total Synth. (-)-calyciphylline N. J. Am. Chem. Soc. 136, 870-873 (2014)

22. Shvartsbart, A. \& Smith, A. B. III. Daphniphyllum alkaloids: Total Synth. (-)-calyciphylline N. J. Am. Chem. Soc. 137, 3510-3519 (2015).

23. For the synthesis of a putative member of calyciphylline B-type alkaloids, see Chattopadhyay, A. K., Ly, V. L., Jakkepally, S., Berger, G. \& Hanessian, S. Total synthesis of isodaphlongamine $\mathrm{H}$ : a possible biogenetic conundrum. Angew. Chem. Int. Ed. 55, 2577-2581 (2016).

24. Yamada, R., Adachi, Y., Yokoshima, S. \& Fukuyama, T. Total synthesis of (-)-daphenylline. Angew. Chem. Int. Ed. 55, 6067-6070 (2016).

25. Chen, X. et al. Divergent total syntheses of (-)-daphnilongeranin B and (-)-daphenylline. Angew. Chem. Int. Ed. 57, 947-951 (2018).

26. Shi, H. et al. Total synthesis of (-)-himalensine A. J. Am. Chem. Soc. 139, 17755-17758 (2017)

27. Xu, B., Wang, B., Xun, W. \& Qiu, F. G. Total synthesis of (-)-daphenylline Angew. Chem. Int. Ed. 58, 5754-5757 (2019).

28. Zhong, J., Chen, K., Qiu, Y., He, H. \& Gao, S. A unified strategy to construct the tetracyclic ring of Calyciphylline A alkaloids: total synthesis of himalensine A. Org. Lett. 21, 3741-3745 (2019).

29. Hugelshofer, C. L., Palani, V. \& Sarpong, R. Calyciphylline B type alkaloids: total syntheses of $(-)$-daphlongamine $\mathrm{H}$ and $(-)$-isodaphlongamine H. J. Am Chem. Soc. 141, 8431-8435 (2019).

30. Hugelshofer, C. L., Palani, V. \& Sarpong, R. Calyciphylline B-type alkaloids: evolution of a synthetic strategy to (-)-daphlongamine H. J. Org. Chem. 84, 14069-14091 (2019)

31. Chen, Y. et al. A concise total synthesis of (-)-himalensine A. Angew. Chem Int. Ed. 58, 7390-7394 (2019).

32. Guo, L.-D. et al. Total synthesis of dapholdhamine B and dapholdhamine B lactone. J. Am. Chem. Soc. 141, 11713-11720 (2019).

33. Guo, L.-D. et al. Enantioselective total synthesis of (-)-caldaphnidine $\mathrm{O}$ via a radical cyclization cascade. J. Am. Chem. Soc. 141, 13043-13048 (2019).

34. Kitabayashi, Y., Fukuyama, T. \& Yokoshima, S. Synthesis of the [7-5-5] tricyclic core of Daphniphyllum alkaloids. Org. Biomol. Chem. 16, 3556-3559 (2018).

35. Hayakawa, R. et al. Toward the synthesis of yuzurimine-type alkaloids: stereoselective construction of the heterocyclic portions of deoxyyuzurimine and macrodaphnine. Org. Lett. 21, 6337-6341 (2019).

36. Solé, D., Urbaneja, X. \& Bonjoch, J. Synthesis of the 4-azatricyclo[5.2.2.0(4,8) undecan-10-one core of daphniphyllum alkaloid calyciphylline A using a Pdcatalyzed enolate alkenylation. Org. Lett. 7, 5461-5464 (2005)

37. Cordero-Vargas, A., Urbaneja, X. \& Bonjoch, J. A stereocontrolled entry to 3 functionalized cis-3a-methyloctahydroindoles: building blocks for daphniphyllum alkaloid synthesis. Synlett, 2007, 2379-2382 (2007).

38. Denmark, S. E. \& Baiazitov, R. Y. Tandem double-intramolecular $[4+2] /[3$ +2 ] cycloadditions of nitroalkenes. studies toward a total synthesis of daphnilactone B: piperidine ring construction. J. Org. Chem. 71, 593-605 (2006).

39. Denmark, S. E., Nguyen, S. T. \& Baiazitov, R. Y. Asymmetric synthesis of the $\mathrm{ABCD}$ ring system of daphnilactone $\mathrm{B}$ via a tandem, double intramolecular, [4 $+2] /[3+2]$ cycloaddition strategy. Heterocycles 76, 143-154 (2008).

40. Denmark, S. E., Baiazitov, R. Y. \& Nguyen, S. T. Tandem double intramolecular $[4+2] /[3+2]$ cycloadditions of nitroalkenes: construction of 
the pentacyclic core structure of daphnilactone B. Tetrahedron 65, 6535-6548 (2009).

41. Coldham, I., Burrell, A. J. M., Guerrand, H. D. S. \& Oram, N. Cascade cyclization, dipolar cycloaddition to bridged tricyclic amines related to the Daphniphyllum alkaloids. Org. Lett. 13, 1267-1269 (2011).

42. Coldham, I., Watson, L., Adams, H. \& Martin, N. G. Synthesis of the core ring system of the yuzurimine-type daphniphyllum alkaloids by cascade condensation, cyclization, cycloaddition chemistry. J. Org. Chem. 76, 2360-2366 (2011).

43. Bélanger, G., Boudreault, J. \& Lévesque, F. Synthesis of the tetracyclic core of Daphnilactone B-type and yuzurimine-type alkaloids. Org. Lett. 13, 6204-6207 (2011).

44. Darses, B. et al. Expedient construction of the [7-5-5] all-carbon tricyclic core of the Daphniphyllum alkaloids Daphnilongeranin B and Daphniyunnine D. Org. Lett. 14, 1684-1687 (2012).

45. Yang, M. et al. Tandem semipinacol-type 1,2-carbon migration/aldol reaction toward the construction of [5-6-7] all-carbon tricyclic core of Calyciphylline A-type alkaloids. Org. Lett. 14, 5114-5117 (2012).

46. Yao, Y. \& Liang, G. Rapid construction of the ABC ring system in the Daphniphyllum alkaloid Daphniyunnine C. Org. Lett. 14, 5499-5501 (2012).

47. Ibrahim, A. A., Golonka, A. N., Lopez, A. M. \& Stockdill, J. L. Rapid access to the heterocyclic core of the Calyciphylline A and Daphnicyclidin A-type daphniphyllum alkaloids via tandem cyclization of a neutral aminyl radical. Org. Lett. 16, 1072-1075 (2014).

48. Kotha, S. \& Ravikumar, O. Diversity-oriented approach to carbocycles and heterocycles through ring-rearrangement metathesis, fischer indole cyclization, and diels-alder reaction as key steps. Eur. J. Org. Chem. 2014, $5582-5590$ (2014)

49. Sakurai, H., Sakabe, N. \& Hirata, Y. X-ray structure determination of yuzurimine hydrobromide. Tetrahedron Lett. 7, 6309-6314 (1966).

50. Zhang, C.-R., Yang, S.-P. \& Yue, J.-M. Alkaloids from the twigs of Daphniphyllum calycinum. J. Nat. Prod. 71, 1663-1668 (2008).

51. Chen, Y. et al. Synthesis of the core structure of Daphnimacropodines. Org Lett. 21, 4309-4312 (2019).

52. Zhang, Y., Guo, L.-D. \& Xu, J. Efficient synthesis of the AC ring system of Daphnilactone B. Youji Huaxue. 39, 1079-1084 (2019).

53. Solé, D., Cancho, Y., Llebaria, A., Moretó, J. M. \& Delgado, A. Intramolecular nitrogen assistance in the nickel-promoted tandem cyclization-capture of amino-tethered vinyl bromides and alkenes. J. Am. Chem. Soc. 116, 12133-12134 (1994)

54. Chamberlin, A. R. \& Chung, J. Enantioselective synthesis of seven pyrrolizidine diols from a single precursor. J. Org. Chem. 50, 4425-4431 (1985).

55. Tominaga, Y., Matsuoka, Y., Kamio, C. \& Hosomi, A. Ketene dithioacetals in organic synthesis: synthesis of silyl ketene dithioacetal and some reactions with substituted benzaldehydes. Chem. Pharm. Bull. 37, 3168-3170 (1989).

56. Okauchi, T., Tanaka, T. \& Minami, T. Lewis Acid-Promoted Deoxygenative $\operatorname{Di}[\beta, \beta$-bis(ethylthio)]vinylation of Aldehydes with Trimethylsilylketene Bis (ethylthio)acetal. J. Org. Chem. 66, 3924-3929 (2001).

57. Saitoh, T., Jimbo, N. \& Ichikawa, J. A novel synthesis of syn and anti $\beta$ hydroxy dithioacetals, masked cross-aldols between aldehydes. Chem. Lett. 33, 1032-1033 (2004).

58. Escalante, L., González-Rodríguez, C., Varela, J. \& Saá, C. Tandem brønsted acid promoted and nazarov carbocyclizations of enyne acetals to hydroazulenones. Angew. Chem. Int. Ed. 51, 12316-12320 (2012).

59. Hargrove, R. \& Stang, P. Vinyl triflates in synthesis. I. tert-Butylacetylene. J. Org. Chem. 39, 581-582 (1974).

60. Cuthbertson, J., Godfrey, A. \& Taylor, R. The preparation of (-)-Grandisine B from $(+)$-Grandisine D; a biomimetic total synthesis or formation of an isolation artefact? Org. Lett. 13, 3976-3979 (2011).

61. Cuthbertson, J., Unsworth, W., Moody, C. \& Taylor, R. The total synthesis of (+)-elaeokanidine A: natural product or isolation artefact? Tetrahedron Lett. 56, 3123-3126 (2015).

62. Gagnier, S. \& Larock, R. Palladium-catalyzed carbonylative cyclization of unsaturated aryl iodides and dienyl triflates, iodides, and bromides to indanones and 2-cyclopentenones. J. Am. Chem. Soc. 125, 4804-4807 (2003).
63. Zeng, M., Murphy, S. \& Herzon, S. Development of a modular synthetic route to (+)-pleuromutilin, (+)-12-epi-mutilins, and related structures. J. Am. Chem. Soc. 139, 16377-16388 (2017).

64. Ren, W. et al. An effective Pd-catalyzed regioselective hydroformylation of olefins with formic acid. J. Am. Chem. Soc. 138, 14864-14867 (2016).

65. Mikołajczyk, M. et al. Organosulphur compounds-XVIIII: A new and general synthesis of ketene s,s- and o,s-thioacetals based on the horner-wittig reaction. Tetrahedron 34, 3081-3088 (1978).

66. Trost, B. \& Kunz, R. Methods in alkaloid synthesis. Imino ethers as donors in the Michael reaction. J. Am. Chem. Soc. 97, 7152-7157 (1975).

\section{Acknowledgements}

Financial support from Shenzhen Science and Technology Innovation Committee (JCYJ20170817110515599, KQJSCX20170728154233200, and

KQTD20150717103157174), NSFC (21772082 and 21971104), Shenzhen Nobel Prize Scientists Laboratory Project (C17783101), Guangdong Innovative Program (No 2019BT02Y335) and Guangdong Provincial Key Laboratory of Catalysis (No. 2020B121201002) are greatly appreciated. We also thank SUSTech CRF NMR facility, Dr. Xiaoyong Chang (SUSTech) for XRD analysis and Dr. Yang Yu (SUSTech) for HRMS analysis.

\section{Author contributions}

J.X. conceived and designed the project and wrote the paper with assistance from L.-D G., Y.Z., and J.H.; L.-D.G., Y.Z, J.H., C.N., H.F., and Y.C. performed the experiments. All authors discussed the results and commented on the manuscript. Y.Z. and J.H. contributed equally to this research.

\section{Competing interests}

The authors declare no competing interests.

\section{Additional information}

Supplementary information is available for this paper at https://doi.org/10.1038/s41467020-17350-x.

Correspondence and requests for materials should be addressed to J.X.

Peer review information Nature Communications thanks the anonymous reviewer(s) for their contribution to the peer review of this work. Peer reviewer reports are available.

Reprints and permission information is available at http://www.nature.com/reprints

Publisher's note Springer Nature remains neutral with regard to jurisdictional claims in published maps and institutional affiliations.

Open Access This article is licensed under a Creative Common Attribution 4.0 International License, which permits use, sharing, adaptation, distribution and reproduction in any medium or format, as long as you give appropriate credit to the original author(s) and the source, provide a link to the Creative Commons license, and indicate if changes were made. The images or other third party material in this article are included in the article's Creative Commons license, unless indicated otherwise in a credit line to the material. If material is not included in the article's Creative Commons license and your intended use is not permitted by statutory regulation or exceeds the permitted use, you will need to obtain permission directly from the copyright holder. To view a copy of this license, visit http://creativecommons.org/ licenses/by/4.0/

(C) The Author(s) 2020 